\title{
MicroRNA-27a participates in the pathological process of depression in rats by regulating VEGFA
}

\author{
JIAN CUI $^{*}$, CUNQI GONG ${ }^{2 *}$, BAORUI CAO ${ }^{2}$ and LONGFEI LI ${ }^{1}$ \\ ${ }^{1}$ Department of Psychiatry, Jining Psychiatric Hospital, Jining, Shandong 272051; ${ }^{2}$ Department of \\ Psychiatry, Zaozhuang Mental Health Center, Zaozhuang, Shandong 277100, P.R. China
}

Received September 27, 2017; Accepted January 19, 2018

DOI: $10.3892 /$ etm.2018.5942

\begin{abstract}
The present study aimed to determine the expression of vascular endothelial growth factor A (VEGFA) and microRNA (miRNA/miR)-27a in hippocampal tissues, and serum from a depression model of rats. In addition, the present study aimed to understand the mechanism of regulation of miR-27a in depression. A total of 40 male rats were selected, and divided into the control and depression model groups. The rats in the model group were subjected to 14 types of stimulations to model depression. By determining the body weight, syrup consumption rate and open field test score, the extent of depression in the rats was evaluated. Quantitative-polymerase chain reaction was used to determine the expression of VEGFA mRNA and miR-27a in hippocampal tissues, and serum. ELISA was used to measure the content of VEGFA protein in serum, while western blotting was employed to determine the expression of VEGFA protein in hippocampal tissues. A dual luciferase assay was carried out to identify the interactions between VEGFA mRNA and miR-27a. The rats in the depression model group showed depression symptoms and the depression model was successfully constructed. Rats with depression had lower VEGFA mRNA and protein expression in the hippocampus, and peripheral blood compared with the control group. Rats in the depression model group had reduced levels of miR-27a in the hippocampus and peripheral blood, which may be associated with the levels of VEGFA. miR-27a was able to bind with the 3'-untranslated region of VEGFA mRNA to regulate its expression. The present study demonstrated that miR-27a expression in hippocampal tissues and blood from rats with depression is upregulated, while the expression of VEGFA mRNA and protein is downregulated.
\end{abstract}

Correspondence to: Dr Baorui Cao, Department of Psychiatry, Zaozhuang Mental Health Center, 6 Huiquan Road, Zaozhuang, Shandong 277100, P.R. China

E-mail: linklink2@163.com

*Contributed equally

Key words: microRNA-27a, depression, VEGFA
miR-27a may participate in the pathological process of depression in rats by regulating VEGFA.

\section{Introduction}

With the increase of competition pressure in modern society, the number of people suffering from depression is growing day by day (1). As a result, research on depression has attracted widespread concerns (2). Pathophysiological studies show that the volume and nerve density of hippocampus in patients with depression are significantly decreased (3-5). Animal model experiments also confirm that hippocampal neurons in depressed rats are disordered and loose, the nuclei of hippocampal neurons are shrunken, the nuclear membrane is irregular and vague, and mitochondria are swelled and denatured $(6,7)$. The etiology of depression is dominated by monoamine hypothesis, which suggests that the decrease of 5-hydroxy tryptamine, norepinephrine and dopamine functions is its pathological mechanism (8). Some studies have focused on the role of neuronal regeneration in the pathogenesis and treatment for depression. According to the neurotrophic hypothesis of depression, brain derived neurotrophic factor (BDNF), tumor necrosis factor- $\alpha$ (TNF- $\alpha)(9)$, vascular endothelial growth factor (VEGF) (10) or fibroblast growth factor 2 (FGF-2) (11) may participate in the progression of depression.

VEGFA is one of the most effective angiogenic growth factors in human body, and its basic mechanism of action is to promote angiogenesis and to increase blood supply (12). However, more and more studies show that VEGFA can affect neurogenesis in a variety of ways, being a multifunctional growth factor (13-15). It is reported that after VEGFA signal transduction enters the cells, it induces the dimerization of ligand and receptor, and then causes phosphorylation of extracellular structure subunits with its receptor to promote the survival, permeability, migration and proliferation of hippocampal neurons (16).

MicroRNA (miRNA or miR) is single-stranded small-molecule RNA (18-25 nucleotides) that exists in eukaryotic cells and regulates gene expression at post-transcriptional levels (17). miRNA plays important roles in nerve cell development, differentiation, proliferation, and apoptosis. It is reported that the expression of some miRNAs is dysregulated in tissues from patients with depression, and downstream targets of the miRNAs are associated with 
depression symptoms (18). miRNA can modulate central nervous activities, including reward feedback, circadian rhythm and cognitive performance, and the abnormalities of these activities are closely related with depression (19-21). miR-27a is a miRNA with abundant functions. Studies show that miR-27a can target epidermal growth factor receptor (EGFR), which is activated in many types of tumors and promotes tumorigenesis $(22,23)$. However, it is never reported whether miR-27a has regulatory effects on VEGFA.

In the present study, we investigate the behaviors of depression rat model, measure the expression of relevant factors in hippocampus and blood of the rats, and try to understand the regulation between miR-27a and VEGFA.

\section{Materials and methods}

Animals. A total of 50 male rats (4-6 weeks old; 180-220 g) were obtained from Chongqing Tengxin Biotech Company (Chongqing, China; http://www.cqtx123.com/) with a certificate no. SCXK(Yu)2016-0018. One week before experiments, the rats had free access to food and water to adapt to the environment. The Reduction, Replacement and Refinement Animal Welfare Principle was followed during the experiments. The present study was approved by the Ethics Committee of Zaozhuang Mental Health Center (Zaozhuang, China).

The 50 rats were first raised in cages with circadian rhythm (5 rats/cage) with free access to food and water for three days. After that, body weight, daily intake of food, tropism of syrup, and distance of spontaneous movement within $5 \mathrm{~min}$ were recorded as baselines. Eight rats were excluded from the experiments due to abnormal baseline activities. In the end, a total of 40 rats with the closest scores were included in the experiments, and randomly and evenly divided into control group and depression model group (20 rats in each group). The rats in control group were raised normally as described above at a density of 5 rats/cage. Rats in depression model group were raised at a density of 1 rat/cage and used to construct depression model according to methods reported by Willner (24). The rats in model group were subjected to 14 types of stimulations, including day/night reverse ( 24 and $48 \mathrm{~h}$ ), repeated tilting of rat cage (direction reverse every 4 for 12 and $24 \mathrm{~h}$ ), water deprivation (6 and $12 \mathrm{~h}$ ), food deprivation (12 and $24 \mathrm{~h}$ ), noise (metal clash for $2 \mathrm{~h}$ and rat yawp for $2 \mathrm{~h}$ ), damp padding (mild and sever for 12 and $24 \mathrm{~h}$ ), foreign matter, no padding, suspension (6 h), tail clamping (mild), cage sharing, horizontal oscillation, cage exchange, and feeding environment change. Each rat was stimulated with only one method on each day, and raised alone in a cage for 35 days. From the fourth week, the general indicators (weight, drink amount and food amount), percentage of syrup consumption, and open field behavior were observed. Body weight, tropism of syrup, and open field behavior were tested for the two groups. After comparing with baseline results, the rats with and without typical depressive symptoms were noted.

To evaluate body weight, the food intake amount and body weight changes of rats within $24 \mathrm{~h}$ (8:00 AM to 8:00 AM on the next day) were recorded on the day before experiment, and days 28 and 35 of the experiment.

To carry out syrup consumption experiment (25), the syrup consumption percentage of rats on the day before experiment, and day 28 and 35 of the experiment were recorded. Total liquid consumption, sugar consumption, pure water consumption, and syrup tropism percentage (syrup consumption/total liquid consumption $\mathrm{x} 100 \%$ ) were calculated.

For open field test, changes in open field behavior of the two groups of rats were recorded on the day before experiment, and days 28 and 35 of the experiment. The dimension of the open field behavior box was $100 \times 100 \times 40 \mathrm{~cm}$ (made by our research group). There were 25 squares with equal sides in the field, and the walls were black. The detailed method was as reported by Lin et al (26). Horizontal score was the number of squares being passed by the rats with four paws. Vertical score was the times of vertical activities (front paws leaving the field or climbing the walls). Total score in the open field test was the sum of horizontal score and vertical score.

After fasting for $12 \mathrm{~h}$ following activity tests, peripheral blood was collected from all rats and serum was separated. Then, the rats were decapitated and hippocampal tissues were collected. All animal experiments were conducted according to the ethical guidelines of Zaozhuang Mental Health Center.

Reverse transcription-quantitative polymerase chain reaction (RT-qPCR). Tissues (100 mg) were ground using liquid nitrogen and mixed with $1 \mathrm{ml}$ TRIzol (10606ES60; Yeasen, Shanghai, China) for lysis. Serum samples $(100 \mu 1)$ were directly mixed with $1 \mathrm{ml}$ TRIzol (10606ES60; Yeasen, Shanghai, China) for lysis. Then, total RNA was extracted using phenol chloroform method. The concentration and quality of RNA was examined using ultraviolet spectrophotometry (Nanodrop ND2000; Thermo Scientific, Waltham, MA, USA). Then, cDNA was obtained by reverse transcription from $1 \mu \mathrm{g}$ RNA and stored at $-20^{\circ} \mathrm{C}$. Reverse transcription of mRNA was performed using TIANScript II cDNA First Strand Synthesis kit (Tiangen, Beijing, China), and reverse transcription of miRNA was carried out using miRcute miRNA cDNA First Strand Synthesis kit (Tiangen).

SuperReal PreMix (SYBR-Green) RT-qPCR kit (Tiangen) was used to detect mRNA expression of VEGFA. The sequences of VEGFA were 5'-CCAGGAGTACCCCGATGA GATAG-3' (upstream) and 5'-CTGGCTTTGGTGAGGTTT GATC-3' (downstream); and those of $\beta$-actin were $5^{\prime}$-ACC CCGTGCTGCTGACGGAG-3' (upstream) and 5'-TCCCGG CCAGCCAGGTCCAT-3' (downstream). PCR reaction system (20 $\mu \mathrm{l})$ for VEGFA determination was composed of $10 \mu \mathrm{l}$ RT-qPCR-Mix, $0.5 \mu 1$ upstream primer, $0.5 \mu \mathrm{l}$ downstream primer, $2 \mu \mathrm{l}$ cDNA and $7 \mu \mathrm{l} \mathrm{ddH}_{2} \mathrm{O}$. PCR conditions for VEGFA determination were: initial denaturation at $95^{\circ} \mathrm{C}$ for $2 \mathrm{~min}$; 40 cycles of $95^{\circ} \mathrm{C}$ denaturation for $30 \mathrm{sec}$, annealing at $58^{\circ} \mathrm{C}$ for $30 \mathrm{sec}$ and elongation at $72^{\circ} \mathrm{C}$ for $30 \mathrm{sec}$ (iQ5; Bio-Rad, Hercules, CA, USA). The $2^{-\Delta \Delta \mathrm{Ct}}$ method was used to calculate the relative expression of VEGFA mRNA against $\beta$-actin. Each sample was tested in triplicate.

Isolation of miR-27a was performed using miRcute miRNA isolation kit (Tiangen). The expression of miR-27a was determined by miRcute miRNA RT-PCR kit (Tiangen), using U6 as internal reference. The sequences of miR-27a were 5'-GCGGCGGTTCACAGTGGCTAAG-3' (upstream) and 5'-ATCCAGTGCAGGGTCCGAGG-3' (downstream); and those of U6 were 5'-CTCGCTTCGGCAGCACATATA CT-3' (upstream) and 5'-ACGCTTCACGAATTTGCGTGT 
3' cgecuugaaUCGGUGACACUu 5' rno-miR-27a | : ||||||||

\section{8:5' aagccagaaAAUCACUGUGAg 3' VEGFA}

Figure 1. Direct interaction between miRNA-27a and VEGFA. Bioinformatics prediction is a powerful tool for the study of the functions of miRNAs. To understand the regulatory mechanism of VEGFA, we used miRanda, TargetScan, PiTa, RNAhybrid and PICTA to predict miRNA molecules that might regulate VEGFA, and found that miR-27a was able to potentially regulate VEGFA. VEGFA, vascular endothelial growth factor A, miRNA, microRNA.

C-3' (downstream). PCR reaction system (20 $\mu \mathrm{l})$ for miR-27a determination was composed of $10 \mu \mathrm{l}$ RT-qPCR-Mix, $0.5 \mu \mathrm{l}$ upstream primer, $0.5 \mu \mathrm{l}$ downstream primer, $2 \mu \mathrm{l}$ cDNA and $7 \mu \mathrm{lddH_{2 }}$ O. PCR conditions for miR-27a determination were: initial denaturation at $95^{\circ} \mathrm{C}$ for $30 \mathrm{sec} ; 45$ cycles of $95^{\circ} \mathrm{C}$ denaturation for $5 \mathrm{sec}$ and annealing at $60^{\circ} \mathrm{C}$ for $30 \mathrm{sec}$ (iQ5; Bio-Rad, Hercules, CA, USA). The $2^{-\Delta \Delta \mathrm{Cq}}$ method was used to calculate the relative expression of miR-27a against U6. Each sample was tested in triplicate.

Western blot analysis. Precooled Radio-Immunoprecipitation Assay (RIPA) lysis buffer $(600 \mu l ; 50 \mathrm{mM}$ Tris-base, $1 \mathrm{mM}$ EDTA, $150 \mathrm{mM} \mathrm{NaCl}, 0.1 \%$ sodium dodecyl sulfate, $1 \%$ TritonX-100, $1 \%$ sodium deoxycholate; Beyotime Institute of Biotechnology, Shanghai, China) was used to lyse the samples. After lysis for $50 \mathrm{~min}$ on ice, the mixture was centrifuged at $12,000 \mathrm{~g} / \mathrm{min}$ and $4^{\circ} \mathrm{C}$ for $5 \mathrm{~min}$. The supernatant was used to determine protein concentration by bicinchoninic acid (BCA) protein concentration determination kit (RTP7102; Real-Times Biotechnology Co., Ltd., Beijing, China). Protein samples $(20 \mu \mathrm{g})$ were then mixed with sodium dodecyl sulfate loading buffer before denaturation in boiling water bath for $5 \mathrm{~min}$. Afterwards, the samples were subjected to $10 \%$ sodium dodecyl sulfate-polyacrylamide gel electrophoresis. The resolved proteins were transferred to polyvinylidene difluoride membranes on ice $(100 \mathrm{~V}, 2 \mathrm{~h})$ and blocked with $5 \%$ skimmed milk at room temperature for $1 \mathrm{~h}$. Then, the membranes were incubated with rabbit anti-mouse VEGFA polyclonal primary antibody (1:1,000; Abcam, Cambridge, UK) and rabbit anti-mouse $\beta$-actin primary antibody (1:5,000; Abcam) at $4^{\circ} \mathrm{C}$ overnight. After extensive washing with phosphate-buffered saline with Tween-20 for 3 times of $15 \mathrm{~min}$, the membranes were incubated with goat anti-rabbit horseradish peroxidase-conjugated secondary antibody (1:3,000; Abcam) for $1 \mathrm{~h}$ at room temperature before washing with phosphate-buffered saline with Tween-20 for 3 times of $15 \mathrm{~min}$. Then, the membrane was developed with enhanced chemiluminescence detection kit (Abcam) for imaging. Image lab v3.0 software (Bio-Rad, Hercules, CA, USA) was used to acquire and analyze imaging signals. The relative content of VEGFA protein was expressed as VEGFA/ $\beta$-actin ratio.

Enzyme-linked immunosorbent assay (ELISA). Serum was examined using VEGFA ELISA kit (Abcam). In microplates, standards $(50 \mu \mathrm{l})$, samples $(10 \mu \mathrm{l}$ sample liquid and $40 \mu \mathrm{l}$ diluent) and blank were set into predefined wells. In the wells for standards and samples, horseradish peroxidase-labelled conjugates $(100 \mu \mathrm{l})$ were added before sealing the plates for incubation at $37^{\circ} \mathrm{C}$ for $1 \mathrm{~h}$. After washing the plates 5 times, substrates A $(50 \mu \mathrm{l})$ and $\mathrm{B}(50 \mu \mathrm{l})$ were added into each well. After incubation at $37^{\circ} \mathrm{C}$ for $15 \mathrm{~min}$, stop solution $(50 \mu \mathrm{l})$ was added into each well, and absorbance of each well was measured at $450 \mathrm{~nm}$ within $15 \mathrm{~min}$.

Bioinformatics. Bioinformatics prediction is a powerful tool for the study of the functions of miRNAs. To understand the regulatory mechanism of VEGFA, we used miRanda (http://www.microrna.org/microrna/home.do), TargetScan (http://www.targetscan.org), PiTa (http://genie .weizmann.ac.il/pubs/mir07/mir07_data.html), RNAhybrid (http://bibiserv.techfak.uni-bielefeld.de/rnahybrid/) and PICTA (http://pictar.mdc-berlin.de/) to predict miRNA molecules that might regulate VEGFA, and found that miR-27a was able to potentially regulate VEGFA (Fig. 1).

Dual luciferase reporter assay. According to bioinformatics results, wild-type (WT) and mutant seed regions of miR-27a in the 3'-UTR of VEGFA gene were chemically synthesized in vitro, added with Spe-1 and HindIII restriction sites, and then cloned into pMIR-REPORT luciferase reporter plasmids. Plasmids $(0.8 \mu \mathrm{g})$ with WT or mutant 3'-UTR DNA sequences were co-transfected with agomiR-27a (100 nM; Sangon Biotech, Shanghai, China) into 293T cells. After cultivation for $24 \mathrm{~h}$, the cells were lysed using dual luciferase reporter assay kit (Promega, Fitchburg, WI, USA) according to the manufacturer's manual, and fluorescence intensity was measured using GloMax 20/20 luminometer (Promega). Using Renilla fluorescence activity as internal reference, the fluorescence values of each group of cells were measured.

Statistical analysis. The results were analyzed using SPSS 18.0 statistical software (IBM, Armonk, NY, USA). The data were expressed as means \pm standard deviations. Data were tested for normality. Multigroup measurement data were analyzed using one-way ANOVA. In case of homogeneity of variance, Least Significant Difference and Student-Newman-Keuls methods were used; in case of heterogeneity of variance, Tamhane's T2 or Dunnett's T3 method was used. $\mathrm{P}<0.05$ was considered to indicate a statistically significant difference.

\section{Results}

Rats in depression model group exhibited depression symptoms and the depression model was successfully constructed. To confirm the successful construction of depression rat model, the body weight, syrup consumption rates and open field test scores of the two groups were compared. The data showed that the body weight of the two groups was not significantly different from each other before stimulations, but the body weight of rats in depression model group was significantly lower than that in control group on days 28 and $35(\mathrm{P}<0.01)$ (Table I). In addition, there was no significant difference in syrup consumption rate between the two groups before stimulations, but the syrup consumption rate in depression model group was significantly reduced than that in control group on days 28 and $35(\mathrm{P}<0.05)$ (Table II). Of note, open field test 
Table I. Body weight.

\begin{tabular}{lcccc}
\hline Groups & No. & Before $(\mathrm{g})$ & Day 28 $(\mathrm{g})$ & Day 35 $(\mathrm{g})$ \\
\hline Control & 20 & $205.21 \pm 23.02$ & $372.58 \pm 35.23$ & $419.59 \pm 36.95$ \\
Depression model & 20 & $199.69 \pm 21.63$ & $315.47 \pm 29.16^{\mathrm{a}}$ & $349.78 \pm 31.03^{\mathrm{a}}$ \\
\hline
\end{tabular}

${ }^{\mathrm{a}} \mathrm{P}<0.01$ compared with control group.

Table II. Syrup consumption rate.

\begin{tabular}{lllll}
\hline Groups & $\mathrm{N}$ & Before $(\%)$ & Day 28 (\%) & Day 35 (\%) \\
\hline Control & 20 & $95.6 \pm 2.3$ & $93.7 \pm 4.2$ & $92.5 \pm 6.2$ \\
Depression model & 20 & $94.9 \pm 2.8$ & $85.5 \pm 6.1^{\mathrm{a}}$ & $79.8 \pm 8.0^{\mathrm{a}}$
\end{tabular}

${ }^{\text {aa }}<0.05$ compared with control group.

Table III. Open field test total score.

\begin{tabular}{|c|c|c|c|c|}
\hline Groups & $\mathrm{N}$ & Before & Day 28 & Day 35 \\
\hline Control & 20 & $130.6 \pm 25.5$ & $123.7 \pm 20.3$ & $118.6 \pm 18.1$ \\
\hline Depression model & 20 & $132.1 \pm 23.6$ & $65.8 \pm 18.9^{a}$ & $59.3 \pm 12.0^{\mathrm{a}}$ \\
\hline
\end{tabular}

${ }^{\text {aa }}<0.01$ compared with control group.

scores of the two groups were not significantly different from each other before stimulations. However, the total score of open field test in depression model group was significantly decreased than that in control group on days 28 and $35(\mathrm{P}<0.01)$ (Table III). These results suggest that the rats in depression model group have shown manifest depression symptoms and the depression model is successfully constructed.

Rats with depression have lower VEGFA mRNA expression in the hippocampus and peripheral blood than control group. To determine the expression of VEGFA mRNA, RT-qPCR was carried out. The data showed that the levels of VEGFA mRNA in hippocampal tissues and serum from the rats in depression model group were significantly lower than those in control group, respectively $(\mathrm{P}<0.01)$ (Fig. 2). The result indicates that rats with depression have lower VEGFA mRNA expression in hippocampus and peripheral blood than control group.

Depression model rats have decreased VEGFA protein expression in the hippocampus and peripheral blood. To measure the expression of VEGFA protein in hippocampal tissues and serum, western blotting and ELISA were performed, respectively. The data showed that VEGFA protein expression in hippocampus and serum from depression model rats were significantly reduced than that from control group $(\mathrm{P}<0.05)$ (Fig. 3). The result suggests that depression model rats have decreased VEGFA protein expression in hippocampus and peripheral blood.
A
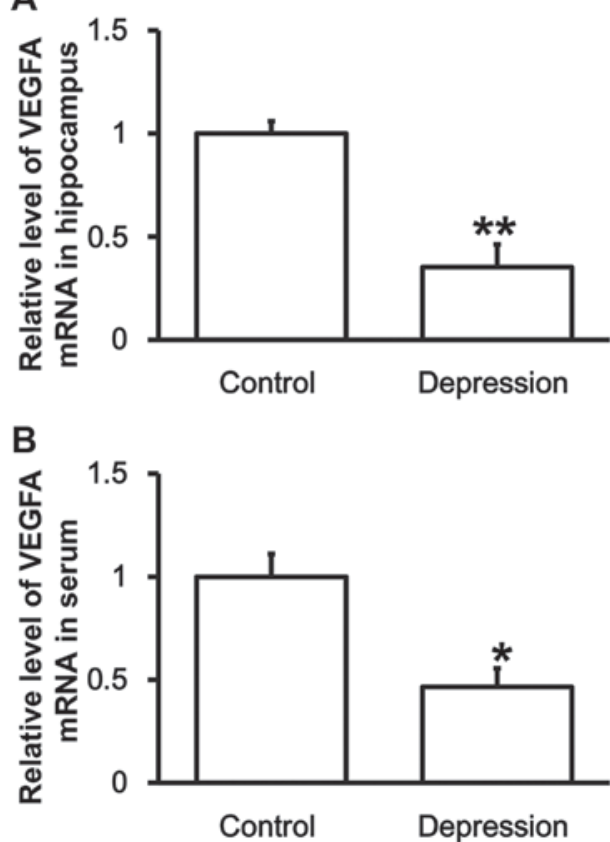

Figure 2. Expression of VEGFA mRNA in (A) hippocampal tissues and (B) serum from rats in control group and depression model group. RT-qPCR was used to measure the expression of mRNA in tissues and serum. ${ }^{*} \mathrm{P}<0.05$ and ${ }^{* *} \mathrm{P}<0.01$ compared with control group. VEGFA, vascular endothelial growth factor A, miRNA, microRNA.

Rats with depression have higher levels of miR-27a in the hippocampus and peripheral blood. To test the expression of miR-27a in hippocampal tissues and serum, RT-qPCR was employed. The data showed that the levels of miR-27a in hippocampal tissues and serum from depression model rats were significantly upregulated compared with those from control group $(\mathrm{P}<0.05)$ (Fig. 4). The result indicates that rats with depression have higher levels of miR-27a in hippocampus and peripheral blood, which may be correlated with the levels of VEGFA.

miR-27a can bind with the 3'-UTR seeding region of VEGFA $m R N A$ to regulate its expression. To identify the interaction between miR-27a and the 3'-UTR of VEGFA mRNA, dual luciferase reporter assay was performed. The fluorescence value of cells co-transfected with agomiR-27a and pMIR-REPORT-WT luciferase reporter plasmids was significantly lower than that in negative control group $(\mathrm{P}<0.05)$. By contrast, the fluorescence value of cells co-transfected with agomiR-27a and pMIR-REPORT-mutant luciferase reporter plasmids was not significantly different from that in negative control group $(\mathrm{P}>0.05)$ (Fig. 5). The result indicates that 

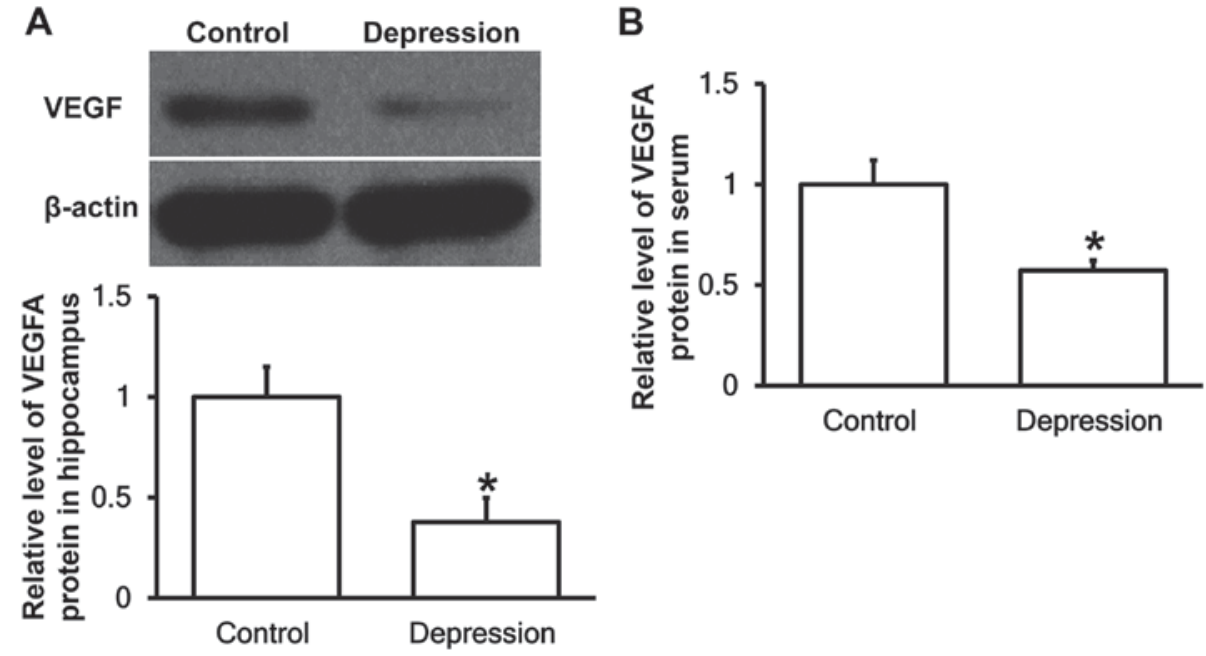

Figure 3. Expression of VEGFA protein in (A) hippocampal tissues and (B) serum from rats in control group and depression model group. VEGFA protein in hippocampal tissues was determined by western blotting, while that in serum was determined by ELISA. "P<0.05 compared with control group. VEGFA, vascular endothelial growth factor A; ELISA, enzyme-linked immunosorbent assay.
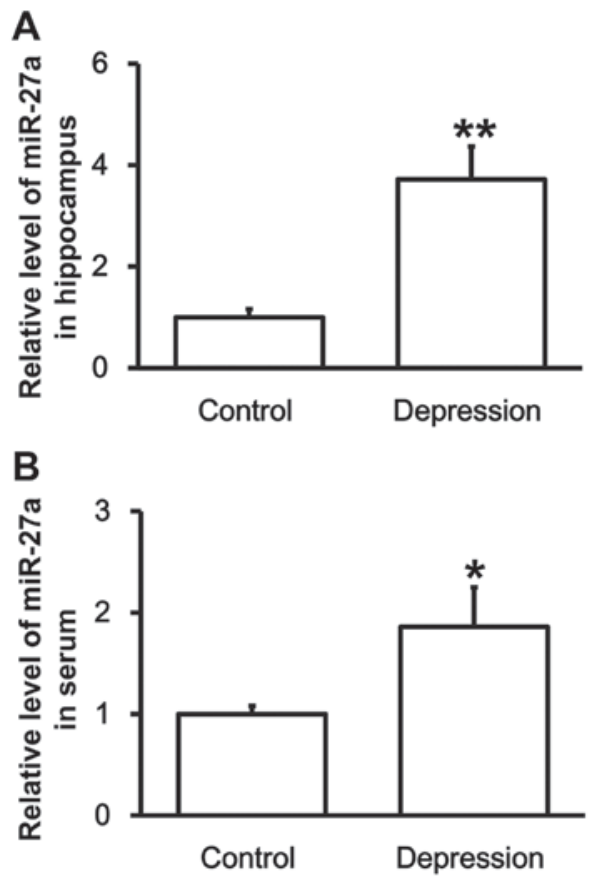

Figure 4. Expression of miR-27a in (A) hippocampal tissues and (B) serum from rats in control group and depression model group. RT-qPCR was used to measure the expression of miR-27a in both types of samples. ${ }^{*} \mathrm{P}<0.05$ and ${ }^{* *} \mathrm{P}<0.01$ compared with control group. mir, microRNA.

miR-27a can bind with the 3'-UTR seeding region of VEGFA mRNA to regulate its expression.

\section{Discussion}

Emotional disorders are usually accompanied by cognitive or behavioral changes or disorders. Cognitive impairment associated with depression mainly includes declines in attention, learning ability and memory. It is reported that learning ability and memory of rats with depression are changed, and this may be caused by damages of limbic system, in which hippocampus is an important component (27). Establishing animal models

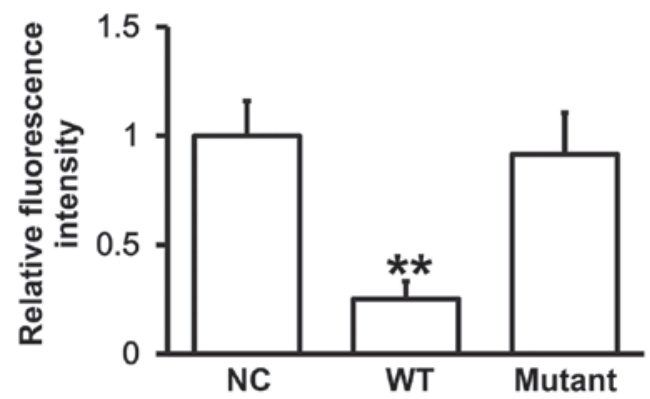

Figure 5. Identification of interaction between miR-27a and VEGFA using dual luciferase reporter assay. Plasmids $(0.8 \mu \mathrm{g})$ with WT or mutant 3'-UTR DNA sequences were co-transfected with agomiR-27a into $293 \mathrm{~T}$ cells. After cultivation for $24 \mathrm{~h}$, the cells were lysed using dual luciferase reporter assay kit, and fluorescence intensity was measured using GloMax 20/20 luminometer. Using Renilla fluorescence activity as internal reference, the fluorescence values of each group of cells were measured. ${ }^{* *} \mathrm{P}<0.01$ compared with NC group. VEGFA, vascular endothelial growth factor A, miRNA, microRNA; WT, wild-type; NC, negative control.

of central nervous diseases is one of the most commonly used research methods (24). Chronic unpredictable mild stress (CUMS) model proposed by Willner (24), and Willner and Mitchell (28) is one of the most widely used models of depression, and we have used this method to construct depression model in the present study. VEGFA receptor, fetal liver kinase-1 (Flk-1), is the major receptor that exerts the biological roles of VEGFA. Flk-1 is mainly expressed in vascular endothelial cells and neuron precursor cells of hippocampus. It is reported that lack of Flk-1 receptors is important for the survival of neural stem cells (29). VEGFA can affect the complex processes of learning and memory (30), and play a role in regulating neurite growth and maturation during brain development (31). The role of VEGFA in neurogenesis may be mediated by its interaction with downstream effector genes (32). In the present study, our data show that VEGF mRNA and protein expression in hippocampal tissues and serum are downregulated in depression model rats, suggesting that downregulation of VEGFA plays a key role in the depression of rats. 
Regulation of mRNA transcription and expression is a complex process of multiple factors. miRNAs cut mRNAs and inhibits their translation to achieve negative feedback regulation $(33,34)$. miRNAs are important regulators in normal development and physiology, and many miRNAs have become biomarkers of various diseases $(35,36)$. Using bioinformatics, we discover that miR-27a is an upstream regulator of VEGFA. miR-27a has various biological functions. It is discovered that miR-27a can regulate the expression of tumor-suppressor gene FOX1 in breast cancer cells (37). In addition, miR-27a inhibits the expression of zinc finger protein ZBTB10, and promotes the accumulation of SP protein in breast cancer cells $(38,39)$, leading to abnormal cell cycles. Single nucleotide polymorphism occurring in miR-27a precursor prevents its transformation to mature form, and families with this have reduced probability of breast cancer (40). By contrast, expression of miR-27 is decreased in several other types of tumors, including acute promyelocytic leukemia (41), colorectal cancer $(42,43)$, malignant melanoma (44), oral squamous cell carcinoma (45) and prostatic carcinoma (46). These reports suggest that miR-27a may also act as a tumor-suppressor in these tumors. miR-27a promotes fibrosis in organs such as liver (47) and lung (48), and is associated with myocardial hypertrophy and heart failure $(49,50)$. Our results in the present study show that VEGFA mRNA and protein expression in depression model rats are downregulated, while miR-27a expression in depression rats is upregulated. Indeed, dual luciferase reporter assay has shown the direct interaction between miR-27a and the 3'-UTR of VEGFA mRNA. Considering the results in open field tests, we discover that miR-27a, VEGFA, and changes in learning ability and memory have regulatory connections with each other.

In conclusion, the present study demonstrates that the mechanism of depression in rats may be the upregulation of miR-27a expression in hippocampal tissues and blood, which results in the downregulation of VEGFA mRNA and protein expression. As a regulator of VEGFA, miR-27a may become a target for the prevention and amelioration of depression.

\section{Acknowledgements}

The present study was supported by Jining Psychiatric Prevention (Jining, China) and Treatment Hospital and Zaozhuang Mental Health Center.

\section{References}

1. Bortolato B, Carvalho AF, Soczynska JK, Perini GI and McIntyre RS: The Involvement of TNF- $\alpha$ in cognitive dysfunction associated with major depressive disorder: An opportunity for domain specific treatments. Current Neuropharmacol 13: 558-576, 2015.

2. Kessler RC: The costs of depression. Psychiatr Clin North Am 35: 1-14, 2012

3. Xie X, Shi Y and Zhang J: Structural network connectivity impairment and depressive symptoms in cerebral small vessel disease. J Affect Disord 220: 8-14, 2017.

4. Suzuki H, Matsumoto Y, Ota H, Sugimura K, Takahashi J, Ito K, Miyata S, Furukawa K, Arai H, Fukumoto Y, et al: Hippocampal blood flow abnormality associated with depressive symptoms and cognitive impairment in patients with chronic heart failure. Circ J 80: 1773-1780, 2016.

5. Nabavi SM, Daglia M, Braidy N and Nabavi SF: Natural products, micronutrients, and nutraceuticals for the treatment of depression: A short review. Nutr Neurosci 20: 180-194, 2017.
6. Li Y, Yan J, Zhu X, Zhu Y, Yao S, Xu Y and Ju S: Dilated Virchow-Robin spaces in the hippocampus impact behaviors and effects of anti-depressant treatment in model of depressed rats. J Affect Disord 219: 17-24, 2017.

7. Hu X, Dong Y, Jin X, Zhang C, Zhang T, Zhao J, Shi J and Li J: The novel and potent anti-depressive action of triptolide and its influences on hippocampal neuroinflammation in a rat model of depression comorbidity of chronic pain. Brain Behav Immun 64: 180-194, 2017.

8. Wang J, Liu Y, Li L, Qi Y, Zhang Y, Li L, Teng L and Wang D: Dopamine and serotonin contribute to Paecilomyces hepiali against chronic unpredictable mild stress induced depressive behavior in Sprague Dawley rats. Mol Med Rep 16: 5675-5682, 2017.

9. Gupta K, Gupta R, Bhatia MS, Tripathi AK and Gupta LK: Effect of agomelatine and fluoxetine on HAM-D score, serum brain-derived neurotrophic factor, and tumor necrosis factor- $\alpha$ level in patients with major depressive disorder with severe depression. J Clin Pharmacol 57: 1519-1526, 2017.

10. Choi M, Lee SH, Chang HL and Son H: Hippocampal VEGF is necessary for antidepressant-like behaviors but not sufficient for antidepressant-like effects of ketamine in rats. Biochim Biophys Acta 1862: 1247-1254, 2016.

11. Wu CK, Tseng PT, Chen YW, Tu KY and Lin PY: Significantly higher peripheral fibroblast growth factor-2 levels in patients with major depressive disorder: A preliminary meta-analysis under MOOSE guidelines. Medicine (Baltimore) 95: e4563, 2016.

12. Roberts E, Cossigny DA and Quan GM: The role of vascular endothelial growth factor in metastatic prostate cancer to the skeleton. Prostate Cancer 2013: 418-340, 2013.

13. Lee BH and Kim YK: Increased plasma VEGFA levels in major depressive or manic episodes in patients with mood disorders. J Affect Disord 136: 181-184, 2012.

14. Nowacka MM and Obuchowicz E: Vascular endothelial growth factor (VEGFA) and its role in the central nervous system: A new element in the neurotrophic hypothesis of antidepressant drug action. Neuropeptides 46: 1-10, 2012.

15. Yasuhara T, Shingo T and Date I: The potential role of vascular endothelial growth factor in the central nervous system. Rev Neurosci 15: 293-307, 2004.

16. Encinas JM, Vaahtokari A and Enikolopov G: Fluoxetine targets early progenitor cells in the adult brain. Proc Natl Acad Sci USA 103: 8233-8238, 2006.

17. Kato $M$ and Slack FJ: microRNAs: Small molecules with big roles-C. elegans to human cancer. Biol Cell 100: 71-81, 2008.

18. Hu Z, Jiang Y, Huo X, Yang Y, Davies H, Botchway BOA and Fang M3: Prospective role of MicroRNAs in depression. Curr Med Chem 24: 3508-3521, 2017.

19. Hansen KF, Karelina K, Sakamoto K, Wayman GA, Impey S and Obrietan K: miRNA-132: A dynamic regulator of cognitive capacity. Brain Struct Funct 218: 817-831, 2013.

20. Hollander JA, Im HI, Amelio AL, et al: Striatal microRNA controls cocaine intake through CREB signalling. Nature 466: 197-202, 2010.

21. Cheng HY, Papp JW, Varlamova O, Dziema H, Russell B, Curfman JP, Nakazawa T, Shimizu K, Okamura H, Impey S and Obrietan K: microRNA modulation of circadian-clock period and entrainment. Neuron 54: 813-829, 2007.

22. Acunzo M, Romano G, Palmieri D, Laganá A, Garofalo M, Balatti V, Drusco A, Chiariello M, Nana-Sinkam P and Croce CM: Cross-talk between MET and EGFR in non-small cell lung cancer involves miR-27a and Sprouty2. Proc Natl Acad Sci USA 110: 8573-8578, 2013.

23. Wang W, Cheng B, Miao L, Mei Y and Wu M: Mutant p53-R273H gains new function in sustained activation of EGFR signaling via suppressing miR-27a expression. Cell Death Dis 4: e574, 2013.

24. Willner P: Validity, reliability and utility of the chronic mild stress model of depression: A 10-year review and evaluation. Psychopharmacology (Berl) 134: 319-329, 1997.

25. Iñiguez SD, Warren BL, Parise EM, Alcantara LF, Schuh B, Maffeo ML, Manojlovic Z and Bolaños-Guzmán CA: Nicotine exposure during adolescence induces a depression-like state in adulthood. Neuropsychopharmacology 34: 1609-1624, 2009.

26. Lin YH, Liu AH, Xu Y, Tie L, Yu HM and Li XJ: Effect of chronic unpredictable mild stress on brain-pancreas relative protein in rat brain and pancreas. Behav Brain Res 165: 63-71, 2005.

27. Lambert KG: Rising rates of depression in today's society: Consideration of the roles of effort-based rewards and enhanced resilience in day-to-day functioning. Neurosci Biobehav Rev 30: 497-510, 2006. 
28. Willner P and Mitchell PJ: The validity of animal models of predisposition to depression. Behav Pharmacol 13: 169-188, 2002.

29. Wada T, Haigh JJ, Ema M, Hitoshi S, Chaddah R, Rossant J, Nagy A and van der Kooy D: Vascular endothelial growth factor directly inhibits primitive neural stem cell survival but promotes definitive neural stem cell survival. J Neurosci 26 6803-6812, 2006.

30. Cao L, Jiao X,Zuzga DS, Liu Y,Fong DM, Young D and During MJ: VEGFA links hippocampal activity with neurogenesis, learning and memory. Nat Genet 36: 827-835, 2004.

31. Wang WY, Dong JH, Liu X, Wang Y, Ying GX, Ni ZM and Zhou CF: Vascular endothelial growth factor and its receptor Flk-1 are expressed in the hippocampus following entorhinal deafferentation. Neuroscience 134: 1167-1178, 2005.

32. Harms KM, Li L and Cunningham LA: Murine neural stem/progenitor cells protect neurons against ischemia by HIF-1 $\alpha$-regulated VEGFA signaling. PLoS One 5: e9767, 2010.

33. Inoue K: MicroRNA function in animal development. Tanpakushitsu Kakusan Koso 52: 197-204, 2007 (In Japanese).

34. Williams AE, Moschos SA, Perry MM, Barnes PJ and Lindsay MA: Maternally imprinted microRNAs are differentially expressed during mouse and human lung development. Dev Dyn 236: 572-580, 2007.

35. Li X, Yu Z, Li Y, Liu S, Gao C, Hou X, Yao R and Cui L: The tumor suppressor miR-124 inhibits cell proliferation by targeting STAT3 and functions as a prognostic marker for postoperative NSCLC patients. Int J Oncol 46: 798-808, 2015.

36. Lv ZC, Fan YS, Chen HB and Zhao DW: Investigation of microRNA-155 as a serum diagnostic and prognostic biomarker for colorectal cancer. Tumour Biol 36: 1619-1625, 2015.

37. Guttilla IK and White BA: Coordinate regulation of FOXO1 by miR-27a, miR-96, and miR-182 in breast cancer cells. J Biol Chem 284: 23204-23216, 2009.

38. Li X, Mertens-Talcott SU, Zhang S, Kim K, Ball J and Safe S: MicroRNA-27a indirectly regulates estrogen receptor $\{$ alpha\} expression and hormone responsiveness in MCF-7 breast cancer cells. Endocrinology 151: 2462-2473, 2010.

39. Mertens-Talcott SU, Chintharlapalli S, Li X and Safe S: The oncogenic microRNA-27a targets genes that regulate specificity protein transcription factors and the G2-M checkpoint in MDA-MB-231 breast cancer cells. Cancer Res 67: 11001-11011, 2007.

40. Yang R, Schlehe B, Hemminki K, Sutter C, Bugert P, Wappenschmidt B, Volkmann J, Varon R, Weber BH, Niederacher D, et al: A genetic variant in the pre-miR-27a oncogene is associated with a reduced familial breast cancer risk. Breast Cancer Res Treat 121: 693-702, 2010.
41. Saumet A, Vetter G, Bouttier M, Portales-Casamar E, Wasserman WW, Maurin T, Mari B, Barbry P, Vallar L, Friederich E, et al: Transcriptional repression of microRNA genes by PML-RARA increases expression of key cancer proteins in acute promyelocytic leukemia. Blood 113: 412-421, 2009.

42. Xi Y, Shalgi R, Fodstad O, Pilpel Y and Ju J: Differentially regulated micro-RNAs and actively translated messenger RNA transcripts by tumor suppressor p53 in colon cancer. Clin Cancer Res 12: 2014-2024, 2006.

43. Volinia S, Calin GA, Liu CG, Ambs S, Cimmino A, Petrocca F, Visone R, Iorio M, Roldo C,Ferracin M, et al: A microRNA expression signature of human solid tumors defines cancer gene targets. Proc Natl Acad Sci USA 103: 2257-2261, 2006.

44. Dai Y, Sui W, Lan H, Yan Q, Huang H and Huang Y: Comprehensive analysis of microRNA expression patterns in renal biopsies of lupus nephritis patients. Rheumatol Int 29: 749-754, 2009

45. Kozaki K, Imoto I, Mogi S, Omura K and Inazawa J: Exploration of tumor-suppressive microRNAs silenced by DNA hypermethylation in oral cancer. Cancer Res 68: 2094-2105, 2008.

46. Prueitt RL, Yi M,Hudson RS, Wallace TA, Howe TM, Yfantis HG, Lee DH, Stephens RM, Liu CG, Calin GA, et al: Expression of microRNAs and protein-coding genes associated with perineural invasion in prostate cancer. Prostate 68: 1152-1164, 2008

47. Ji J,Zhang J, Huang G, Qian J, Wang X and Mei S: Over-expressed microRNA-27a and $27 \mathrm{~b}$ influence fat accumulation and cell proliferation during rat hepatic stellate cell activation. FEBS Lett 583: 759-766, 2009.

48. Kang BY, Park KK, Green DE, Bijli KM, Searles CD, Sutliff RL and Hart CM: Hypoxia mediates mutual repression between microRNA-27a and PPAR $\gamma$ in the pulmonary vasculature. PLoS One 8: e79503, 2013

49. Hernandez-Torres F, Aranega AE and Franco D: Identification of regulatory elements directing miR-23a-miR-27a-miR-24-2 transcriptional regulation in response to muscle hypertrophic stimuli. Biochim Biophys Acta 1839: 885-897, 2014.

50. Roncarati R, Viviani Anselmi C, Losi MA, Papa L, Cavarretta E, Da Costa Martins P, Contaldi C, Saccani Jotti G, Franzone A, Galastri L, et al: Circulating miR-29a, among other up-regulated microRNAs, is the only biomarker for both hypertrophy and fibrosis in patients with hypertrophic cardiomyopathy. J Am Coll Cardiol 63: 920-927, 2014.

This work is licensed under a Creative Commons Attribution-NonCommercial-NoDerivatives 4.0 International (CC BY-NC-ND 4.0) License. 